\title{
INFLUÊNCIA DA AUTORREGRA DE ADAPTAÇÃO SITUACIONAL PARA A VIDA DO INDIVÍDUO IMPACTANDO NO SETOR ORGANIZACIONAL DO TRABALHO
}

\author{
Fabiana Gilda Maria de Oliveira ${ }^{1}$
}

RESUMO: O foco principal deste artigo é refletir sobre o impacto da elaboração de novas regras adaptativas na vida do indivíduo. Este artigo tem como objetivo repercutir sobre a influência de regras com flexibilidade em mudanças perante as situações problemas exprimindo no contexto organizacional do trabalhador. Realizou-se uma pesquisa bibliográfica considerando as contribuições de autores como BANHATO (2019), CAVALHEIRO (20II), SANZOVO (2007), entre outros, procurando ressaltar a relevância em analisar que dependendo de quais são as autorregra que o trabalhador tenha fixado poderá influenciar no seu desenvolvimento com o trabalho e também em sua saúde mental. Conclui-se a pertinência de analisar o desenvolvimento no trabalho com uma percepção ampla, dando ênfase a todos os setores da vida do indivíduo em que consiste como biopsicossocial, levando em consideração que estão articulados.

Palavras-chaves: Impacto. Influência. Autorregra. Trabalho.

ABSTRAT: The main focus of this article is to reflect on the impact of the elaboration of new adaptive rules in the individual's life. This article aims to reflect on the influence of rules with flexibility in changes in the face of problem situations expressing in the organizational context of the worker. A bibliographic research was carried out considering the contributions of authors such as (BANHATO (2019), CAVALHEIRO (20II), SANZOVO (2007), among others, seeking to emphasize the relevance of analyzing that depending on which self-rule the worker has set may influence their development wich work and also their mental health. It is concluded that it is appropriate to analyze development at work with a broad perception emphasizing all sectors of the individual's life in which he or she is biopsychosocial taking into account that they are articulated.

Keywords: Impact. Influence. Self-rule. Work.

\footnotetext{
${ }^{I}$ Formação acadêmica: Pós-graduação. Instituto Prominas Serviços Educacionais LTDA. E-mail: fabiana.gmoliveira@hotmail.com.
} 


\section{INTRODUÇÃO}

O presente trabalho tem como tema a importância da elaboração da autorregra adaptativa situacional na vida como um todo do indivíduo, impacto com isso na relação do trabalho organizacional.

Neste Ponto de vista, abrangem as questões que serão conduzidas neste trabalho:

- O impacto da regra de adaptação a mudanças situacionais na vida do indivíduo?

- Quais prejuízos em não ter fixada a autorregra adaptativa na relação do trabalhador com o trabalho na organização?

- Os prejuízos em não ter a autorregra de adaptação situacional impactando na saúde mental do trabalhador?

Quando se expõe sobre mudanças é indispensável articular sobre a relevância da fixação de regra adaptativa no quesito saúde mental do trabalhador. No qual lembrando que se o trabalhador estiver em adoecimento, isso poderá implicar na produtividade da organização do trabalho. Desta forma, é relevante a investigação do que de fato pode impactar na saúde como um todo do trabalhador, lembrando que somos seres biopsicossociais.

Alguns autores relatam sobre o impacto da saúde mental do trabalhador na organização do trabalho. Sendo que Caso o trabalhador não tenha condições de lhe dar com mudanças, causa um aumento significativo do stress, no qual poderá promover um adoecimento mental, com isso trará também impacto produtivo na organização do trabalho. Isso ocorre quando o stress a mudanças situacionais acontece, mas o indivíduo não consegue se adaptar a tais mudanças, desencadeando possível adoecimento mental do trabalhador. Ou seja, se a autorregra adaptativa estiver fixada, a possibilidade de adoecimento mental torna-se menor.

Como menciona (CAVALHEIRO, 20II), o afastamento de trabalhadores devido ao adoecimento mental é algo que vem acontecendo em recorrência nas organizações do trabalho. Devido a este fato, está sendo estudado sobre a influência da associação do trabalho em desencadear tais transtornos, como também, 
investigando como tem sido as configurações das tarefas, se é possível que venha provocar algum adoecimento mental para o trabalhador. Quando se refere a stress do trabalhador já confirmam a hipótese do impacto de mudanças situacionais provocarem aumento significativo na vida como um todo do trabalhador, no qual tem provocado prejuízos tanto para o trabalhador, quanto para a organização do trabalho (PEREIRA, 20I0).

Conforme Sanzovo,

Estando o stress relacionado a alterações ambientais aversivas perante as quais o indivíduo precisa apresentar respostas de adaptação, eventos que demandem algum tipo de adaptação por parte do indivíduo podem ser considerados estressores (Sanzovo,c.e.,p.2)

Neste contexto, o objetivo principal deste estudo é argumentar o quanto faz se necessário que os trabalhadores desenvolvam a autorregra adaptativa situacional, para promover saúde mental aos mesmos e o quanto isso impacta na qualidade do trabalho organizacional. Para atingir os objetivos propostos foi utilizado como pesquisa bibliográfica a partir da análise minuciosa de materiais em publicações literárias publicadas em artigos científicos divulgados no meio eletrônico. $\mathrm{O}$ texto final foi fundamentado nas críticas e parecer de autores como: Sanzovo (2007), Banhato (2019), Cavalheiro (2011), Pereira (2010), DSM V (2014), Simões (2013), Souza (2002).

\section{DESENVOLVIMENTO}

Emoção provém do latim emotione que, por sua vez, é derivada de ex (fora, para fora) motio (movimento, ação, comoção, gesto). É um movimento de dentro para fora, uma forma do individuo se comunicar entre os comportamentos internalizados em si com o ambiente, resultando na ativação de uma rede neural complexa e elaborada (BANHATO,2019).

Do ponto de vista biológico, refere-se a um conjunto de reações químicas que ativam o sistema neural do indivíduo, no qual é associado a uma organização de certas respostas comportamentais básicas e necessárias à sobrevivência (BANHATO,2019). 
Em Psicologia, emoção é definida como uma experiência subjetiva ao individuo, também denominado comportamento privado, na qual estimula a ativação fisiológica e a manifestação de comportamentos públicos. É uma resposta estímulos externos e internos que resulta em reações comportamentais públicos e privados como fisiológicas cognitivas, e afetivas (CAVALHEIRO, 20II).

Segundo a neurociência as emoções têm a capacidade de motivar as pessoas a exercerem ações decisivas para a sobrevivência. $O$ que acontece quando reagimos com fuga devido ao medo de determinado animal, algo que se não fizéssemos poderíamos vir a morrer. Neste caso o comportamento de medo é indispensável. Vale salientar a importância das emoções em proporcionar a estimulação de regiões neurais que nos direcionam a raciocinar, nos conduzindo com isso a compreender o mundo à nossa volta. como também é um comportamento que nos auxiliam na resolução de problemas .(BANHATO 2019).

A tristeza é uma emoção primária sendo chamada pelo senso comum como sensação de desprazer e usualmente relacionada a uma perda. Normalmente é manifesto no ambiente pelo comportamento de encolhimento introspectivo, choro, diminuição de ânimo, vigor e prazer, bem como alterações no apetite e sono (CAVALHEIRO, 20II).

\section{RELAÇÃO DOS COMPORTAMENTOS PRIVADO COM O NÃO PRIVADO PARA O ADOECIMENTO MENTAL DO TRABALHADOR}

Quando se procura estudar as emoções, busca em entender seus mecanismos de ações no indivíduo e isso é extremamente importante para refletir através da mesma, a forma como o indivíduo responde ao estímulo fornecido pelo meio, interfere no controle das emoções (CAVALHEIRO,20II), Ou seja, a forma como o indivíduo vivencia as situações moldam seus comportamentos, nos quais são constituídos através de suas experiências anteriores, conhecimentos prévios e significados a partir de observações próprias da realidade (PERREIRA,20Io).De acordo com a Análise Comportamental, o processo de stress pode ser compreendido como uma modificação na relação do sujeito com o ambiente por causa de alterações ambientais aversivas,tornando-se preciso a elaboração de um novo repertório. Se o 
indivíduo, perante de uma alteração ambiental aversiva, não constituir respostas comportamentais adaptativas, pode-se considerar que essa ausência de resposta se constituirá como chamado no senso comum a existência de um problema, gerando como resposta possíveis emoções, que podem induzir o indivíduo a fuga ou esquina da situação aversiva (PERREIRA,2010). Neste caso o indivíduo poderá desenvolver a regra de que a situação vivenciada não tem resolução. Vale ressaltar que a forma como cada indivíduo aprendeu a manejar situações de stress, determinará se o acontecimento é aversivo ou não, ou seja isso é uma regra que pode ser aprendida e modificada (SANZOVO,2007).

\section{BENEFÍCIO DA ELABORAÇÃO DA AUTORREGRA ADAPTATIVA SITUACIONAL}

Quando o indivíduo aprende a ter domínio sobre os eventos de stress, compreenderá que é possível ter controle sobre alguns eventos do ambiente, já o indivíduo que não tem este domínio, desenvolverá a regra em que não tem controle sobre nenhum evento em sua vida. Podendo se entender então que quando o indivíduo desenvolve a regra que é possível modificar o ambiente de forma resolutiva para situações aversivas, reduz a ocorrência de respostas negativas, como exemplo os pensamentos e emoções aversivas. Vale salientar a importância do indivíduo em se comportar de alguma forma que possibilite maior adaptação diante de mudanças de repertório, aprimorando com isso comportamentos mais assertivos (SANZOVO, 2007). Aprender a controlar as situações favorece o não adoecimento do indivíduo, no qual traz impactos em todos os âmbitos, sendo eles biopsicossocial. Isso é perceptivo quando o indivíduo manifesta prejuízos no convívio social, saúde física e psicológica. Quanto ao aspecto organizacional apresenta dificuldades em resolução de problemas (PERREIRA,20I0).

A origem do stress podem ser externas e internas, as externas englobam situações que não dependem diretamente do controle do indivíduo, isto é, mudanças inesperadas, problemas do cotidiano, acidentes ou doenças, por exemplo. Já as internas estão diretamente relacionadas à pessoa e aos comportamentos privados, podendo constituir- -se do padrão comportamental apresentado, nível de 
assertividade, vulnerabilidade, entre outros (SANZOVO,2007). No que se refere a isto, algo problemático no âmbito do trabalho pode acontecer se o Indivíduo não desenvolver regras de adaptação, todas as vezes que surgir situações que demandam mudanças, ocasionará comportamentos privados então chamados de sentimentos de incerteza, confusão e frustração entre outros, nos quais geram pensamentos vagos e sem foco sobre o problema. À medida que o conhecimento sobre a problemática fica mais clara, sentimentos de confiança e certeza aumentam. Em alguns setores organizacionais essa adaptação é indispensável para que haja desenvolvimento empresarial e preservação da saúde dos trabalhadores, isto devido ao surgimento de melhorias e adaptações ás mudanças que ocorrem no mercado de trabalho (PERREIRA, 2010).

Para o analista do comportamento, as variáveis relacionadas no desenvolvimento e manutenção de comportamentos desadaptativos se encontram no ambiente imediato e na história do indivíduo. Portanto, os eventos que promovem aumento das emoções aversivas, são analisados de acordo com essa história e com as contingências presentes no momento na vida da pessoa. O comportamento privado chamado de emoção ocorrerá associado à sensibilidade às contingências geradoras de stress, ou seja, diferencia-se de acordo de com a condição genética do indivíduo e, principalmente, de sua história ambiental (SANZOVO, 2007).

Souza (2002, p.3) enfatiza o conceito sobre Burnout:

Como síndrome de exaustão, despersonalização e baixa realização pessoal com o trabalho, que pode ocorrer com indivíduos que trabalham para pessoas, especialmente para as que têm algum tipo de problema. A exaustão refere-se ao sentimento de sobrecarga emocional e de esgotamento e é a dimensão que mais se aproxima de uma variável de estresse (SOUZA w.c., p.3).

O adoecimento patológico no setor organizacional é algo que já esta sendo estudado há bastante tempo. Uma das síndromes que acometem os trabalhadores é a síndrome de Burnout, caracterizada por exaustão, despersonalização e baixa realização pessoal com o trabalho, no qual tem promovido muitos prejuízos tanto para o trabalhador, quanto para organização, porém todas as áreas da vida do indivíduo são afetadas, conhecido como biopsicossocial (SOUZA, 2002). 
O trabalho proporciona tarefas que promovem pressões psíquicas que necessitarão de adaptações situacionais para se adequar, fornecendo possivelmente um aumento de algumas emoções, nas quais se o indivíduo não tiver a regra de se adaptar a novas mudanças, isso desencadear um desequilíbrio psíquico, sendo chamado pela ciência médica de aumento da ansiedade, que é composta por reações químicas liberadas no organismo do indivíduo, provocando uma série de sintomas psicossensoriais, se não for controlado, isso irá prejudicar a saúde do indivíduo como um todo, ou seja, em todas as esferas biopsicossociais (SIMÕES, 2013). Como por exemplo, os sintomas que caracterizam um aumento da ansiedade: dificuldade em concentração, insônia ou sono demasiado, redução ou aumento do apetite, diminuição da disposição, como também nas relações sociais e produção de trabalho (DSM 5, 2014).

A ansiedade foi mencionada neste artigo devido ser uma reação química que acomete todos os seres humanos, em que ao vivenciar uma situação nova na qual necessita de mudanças para solucionar, até analisar a situação, gera associado a isto pensamentos vagos sobre as possíveis soluções e manifestação de algumas emoções, como exemplo o medo da frustração, como também antecipação do perigo, isso por ser algo desconhecido ou estranho para o indivíduo. Porém quando o indivíduo tem a regra de adaptação bem fixada, esse aumento de ansiedade é reduzido assim que soluciona a situação problema (DSM 5, 2014).

\section{CONSIDERAÇÕES FINAIS}

Conforme o assunto abordado, conclui-se que as emoções por si só não podem ser determinadas como causadoras inicialmente de adoecimento mental, desta forma é preciso ser analisada em conjunto com as vivências anteriores na vida do indivíduo, como também a situação do ambiente atual. Isso devido ser individualizado a analise, por ter que fazer a junção destes três aspectos no indivíduo, no qual demonstrará qual a significação que o mesmo aprendeu com as suas vivências, incluindo as autorregras utilizadas nas situações problemas. Lembrando que essa habilidade pode 
ser aprendida no decorrer da vida, quando o indivíduo faz terapia comportamental, isso pode ser elaborado.

Quanto ao adoecimento mental do trabalhador na instituição organizacional do trabalho, requer averiguar vários fatores que podem influenciar tal acontecimento, ou seja, não é cabível estabelecer a causalidade baseada somente com a visão fixada no setor organizacional. Lembrando que cada indivíduo é caracterizado nas três esferas denominado biopsicossocial, em que uma esfera poderá influenciar a outra na elaboração e execução comportamental.

Vale ressaltar a importância em que o indivíduo trabalhador venha fixar a regra de adaptação situacional, promovendo a redução de probabilidade em desencadear um adoecimento mental do trabalhador, como também o aumento da qualidade produtiva do mesmo na organização do trabalho.

\section{REFERÊNCIAS}

BANHATO, Eliane Ferreira Carvalho. Reflexões sobre os benefícios da tristeza segundo a neurociência e a arte fílmica divertida mente. CES Revista, v. 33, n. 2, p. 34-7-8, 2019. Disponível em: < file:///C:/Users/sinthia.moura/Desktop/2283-517I-ISM.pdf > Acessado em or de outubro de 2021.

CAVAlHEIRO, Gabriela; TOLFO, Suzana da Rosa. Trabalho e depressão: um estudo com profissionais afastados do ambiente laboral. Psico-Usf, v. 16,n.2, p. 2-3, 2orr.disponível em:

〈https://www.scielo.br/j/pusf/a/vCXsfpGWPZCRksyZGnQbmmk/?format=pdf \&lang=pt $>$ acessado em 29 de setembro de 2021.

ENUMO, Sônia Regina Fiorim et al. Enfrentando o estresse em tempos de pandemia: proposição de uma cartilha. Estudos de Psicologia (Campinas), v. 37,p.2-34, 2020.disponível em:

〈https://www.scielo.br/j/estpsi/a/mwXhYmkmwJspgnDJjsJwFjk/?lang=pt\&form at $=\mathrm{pdf}>$ acessado em 03 de outubro de 2021.

Manual diagnóstico e estatístico de transtornos mentais [recurso eletrônico]: DSM-5 / American Psychiatric Association ; tradução: Maria Inês Corrêa Nascimento ... et al.] ; revisão técnica: Aristides Volpato Cordioli ... [et al.]. - 5. ed. - Dados eletrônicos. - Porto Alegre: Artmed, sed, p.93-99-I23, 2014. Disponível em: <http://www.niip.com.br/wp-content/uploads/2018/o6/Manual-Diagnosico-eEstatistico-de-Transtornos-Mentais-DSM-5-I-pdf.pdf> acessado em 04 de outubro de 2021. 
PEREIRA, Frederico Cesar Mafra. Necessidades e usos da informação: a influência dos fatores cognitivos, emocionais e situacionais no comportamento informacional de gerentes. Perspectivas em Ciência da informação, v. 15, p.4-5-6-7, 2010. Disponível em:

〈https://www.scielo.br/j/pci/a/LKnvCSssJXLwsqBb4nk7BHN/abstract/?lang=pt〉 acessado em 29 de setembro de 2021.

SANZOVO, Cristiane Élis et al. Estressores e estratégias de coping em uma amostra de psicólogos clínicos. Estud. psicol. (Campinas) 24 (2) p.2-3, Jun 2007. Disponível em 〈https://www.scielo.br/j/estpsi/a/8JMhXG9gCLDTPpx447F5hPR/?lang=pt〉 acessado em 03 de outubro de 2021.

Simões, Fátima Itsue Watanabe; Hashimoto, Francisco. Adoecimento no trabalho: um estudo de caso. Revista Laborativa, v. 2, n. 2, p. 3, 2013. Disponível em: $\langle$ http://hdl.handle.net/II449/126925 >. Acessado em o2 de outubro de 202I.

SOUZA, Wilma Costa; SILVA, Angela Maria Monteiro. A influência de fatores de personalidade e de organização do trabalho no burnout em profissionais de saúde. Estudos de Psicologia (Campinas), v. 19, p. 3-4, 2002.Disponível em:< https://www.scielo.br/j/estpsi/a/WXWNj9gGRjWZfBWzzMXdV8f/?lang=pt > Acessado em 04 de outubro de 2021. 